\title{
Conversão do conhecimento é fonte de Vantagem Competitiva Sustentável? Uma análise empírica sob a perspectiva da Resource-based View
}

\author{
Is knowledge conversion a source of Competitive \\ Sustainable Advantage? An empirical analysis based \\ from a Resource-based View perspective
}

\author{
Silvio Popadiuk ${ }^{1}$ \\ Giancarlo Ricciardi²
}

\begin{abstract}
Resumo: Distinções entre Vantagem Competitiva (VC) e Vantagem Competitiva Sustentável (VCS), apresentadas por Wernerfelt (1984, 1995), Barney (1986a, 1986b, 1991) e Barney e Arikan (2001), indicam que a VCS tende a resistir às tentativas de duplicação. Com o presente estudo, foi analisado se o modelo SECI de conversão do conhecimento (NONAKA; TAKEUCHI, 2004) é avaliado pelos gestores organizacionais como uma fonte de VCS, segundo a perspectiva da Resource-based View $(R B V)$. Por meio de estudo de campo, mediante a aplicação de um questionário estruturado fechado junto a 200 gestores, concluiu-se que a visão do gestor é divergente dos indicadores conceituais que qualificam o modelo SECI como vetor de Vantagem Competitiva Sustentável na perspectiva da RBV. Em outras palavras, enquanto a literatura afirma que o modelo SECI é gerador VCS, no presente estudo identificou-se que a opinião dos gestores não converge para essa afirmação, sugerindo que, na prática, a teoria é outra.
\end{abstract}

Palavras-chave: Modelo SECI. Vantagem Competitiva Sustentável. Visão baseada em recursos. Conversão do conhecimento.

\begin{abstract}
The distinction between competitive advantage and competitive sustainable advantage (CSA) as presented by Wernerfelt (1984, 1995), Barney (1986a, 1986b, 1991, and Barney and Arikan (2001) indicates that CSA tends to resist duplication. The purpose of the present study is to analyze how the SECI model (Nonaka and Takeuchi, 2004) has been evaluated by managers as a CSA source using from a Resource-based View perspective (RBV). A structured questionnaire with closed questions was administered to 200 managers. The questionnaire allowed the analysis of the manager's view about the indicators that qualify the SECI model as a CSA source according to a RBV perspective. In other words, while the literature supports the idea that the SECI model develops CSA, the present study identified that the managers have a divergent view. This suggests that practices differ from theory.
\end{abstract}

Keywords: SECI Model. Competitive Sustainable Advantage. Resource-based View. Resources. Knowledge conversion

\section{Introdução}

A turbulência e o dinamismo dos mercados na atualidade têm se revelado importantes fatores de aumento de competitividade entre as corporações que buscam, cada vez mais, a satisfação de seus consumidores e, por meio dela, a obtenção de uma Vantagem Competitiva Sustentável (WEISSENBERGER-EIBL; SCHWENK, 2009).

A Vantagem Competitiva (VC), segundo Barney (1991), advém da impossibilidade de concorrentes de dada empresa implementarem estratégias de criação de valor simultaneamente. Contudo, tal vantagem não elimina, ou adia, a ação competitiva da concorrência, que pode desenvolver estratégias de criação de valor similares, ou substitutas, às de dada empresa, obtendo resultados equivalentes ou superiores. Já a Vantagem Competitiva Sustentável (VCS) está condicionada à incapacidade de as empresas concorrentes obterem resultados análogos aos de dada empresa, mesmo que implementem estratégias de criação de valor semelhantes (THERIOU; AGGELIDIS; THERIOU, 2009).

\footnotetext{
${ }^{1}$ Universidade Presbiteriana Mackenzie, Rua da Consolação, 896, Sala H, Bloco 27, CEP 01.302-907, São Paulo - SP, E-mail: spopadiuk@mackenzie.br

${ }^{2}$ Universidade São Judas Tadeu, Av. Senador Casemiro Da Rocha, 713, CEP 04047-001, São Paulo - SP,

E-mail: giancarlo.ricciardi@uol.com.br
}

Recebido em 18/3/2008 — Aceito em 24/2/2011

Suporte financeiro: MACKPESQUISA - Fundo de apoio à Pesquisa da Universidade Presbiteriana Mackenzie. 
A obtenção da Vantagem Competitiva está criticamente condicionada à obtenção e retenção de recursos o que, na definição de Grant (2002), pode assumir duas classificações distintas: i) recursos intangíveis, facilmente identificáveis de forma objetiva e; ii) recursos intangíveis, assim tipificados por sua difícil mensuração e identificação. Collins (1994) destaca que a efetiva Vantagem Competitiva é obtida apenas por meio dos recursos intangíveis, uma vez que os recursos tangíveis, por sua natureza, podem ser facilmente identificados e copiados. Por suas características intrínsecas, os recursos tangíveis dificilmente têm sua origem compreendida e, portanto, dificilmente serão copiados (WERNERFELT, 1995; (WEISSENBERGER-EIBL; SCHWENK, 2009).

Para Hitt, Ireland e Hoskinsson (2002), os recursos tangíveis são os bens que podem ser vistos e quantificados. Os recursos intangíveis são bens que se encontram profundamente enraizados na história da empresa, que se acumularam com o passar do tempo e são caracterizados como conhecimentos, confiança recíproca entre colaboradores e ideias.

Partindo-se de definições propostas por diversos autores (WERNERFELT, 1984; RUMELT, 1984; BARNEY, 1991) para os recursos - ativos tangíveis e intangíveis que permitem às firmas conceber e programar suas estratégias (BARNEY; ARIKAN, 2001) -, compreende-se sua importância para a concepção de estratégias que conduzem as firmas à obtenção de Vantagem Competitiva Sustentável. Nesse sentido, dentre o conjunto de ativos intangíveis presentes numa organização (processos, rotinas, reputação etc.), o conhecimento e suas formas de conversão tornam-se um dos recursos intangíveis que pode ser caracterizado como fonte de Vantagem Competitiva Sustentável (WEISSENBERGER-EIBL; SCHWENK, 2009).

Portanto, para o desenvolvimento deste trabalho parte-se do pressuposto de que: i) um dos componentes do conhecimento é a informação; ii) o conhecimento tem importante papel no processo tanto de análise quanto interpretação do ambiente no qual a corporação se insere; iii) é importante fator para a ação organizacional; iv) caracteriza-se como recurso intangível, e um vetor para a obtenção de Vantagem Competitiva Sustentável.

Nesse contexto, o objetivo principal deste trabalho foi identificar em que medida a visão do gestor e a teoria a respeito da associação entre a criação de conhecimento e a obtenção de Vantagem Competitiva Sustentável são convergentes. Para isso, nos próximos tópicos são apresentadas as considerações teóricas associadas para Resource-based View (RBV) e ao conhecimento, bem como as questões de caráter metodológico que permitiram a execução da fase empírica do estudo.

\section{Fundamentação téorica}

\subsection{Competitividade e Resource-based View}

A perspectiva histórica de fundamentação da RBV, segundo Barney e Arikan (2001), é originada a partir de quatro fontes primordiais: o estudo das competências distintivas; teorias Ricardianas; teorias Penrosianas; e o estudo das implicações econômicas de políticas antitruste.

Essa visão econômica conduziu Bain (1956) à elaboração do modelo Structure-Conduct-Performance $(S C P)$. Esse modelo sugere que a estrutura de uma indústria define a amplitude de atuação de uma firma - sua conduta - e a sua performance dentro da indústria. Firmas que operam em indústrias que tenham estruturas diferentes da perfeita competição têm opções de conduta que irão capacitá-las a obter níveis de performance que reduzirão o bem estar da sociedade de modo significativo. No extremo, esta visão dos determinantes de performance da firma sugerem que qualquer performance superior persistente vivenciada por uma firma, por definição, reflete na conduta não competitiva de outra firma, o que se mostra antagônica ao bem estar da sociedade (BARNEY; ARIKAN, 2001; ELG, 2007; HO, 2009).

Citando Harold Demsetz, Barney e Arikan (2001) consideram que esse pesquisador, em 1973, antecipou a lógica da RBV ao enunciar que a estrutura da indústria não era o único determinante da performance de uma firma. Algumas firmas podem obter performances persistentemente superiores por terem sorte ou por serem mais competentes do que suas concorrentes no que tange ao atendimento das necessidades dos consumidores.

Wernerfelt (1984), tido como o precursor da teoria da RBV, aponta para algumas questões-chave que a teoria dos recursos, baseada na visão de Penrose (1959), deveria responder: i) em quais dos seus atuais recursos a firma deve buscar diversificação; ii) quais recursos deveriam ser desenvolvidos por meio da diversificação; iii) em qual sequência e em quais mercados a diversificação deve ocorrer; e iv) quais tipos de firmas seriam alvo de possíveis aquisições.

A lógica dominante na RBV parte do pressuposto da heterogeneidade e imobilidade de recursos. Segundo Barney (1991), seria bastante improvável que empresas inseridas numa mesma indústria, que dispusessem exatamente dos mesmos recursos, apresentassem performances diferentes. Tal situação mostra-se improvável, tendo em vista que todas as empresas dessa indústria teriam acesso aos mesmos tipos de recursos, estando, assim, capacitadas a implementar as mesmas estratégias de criação de valor. Uma exceção é apresentada: a vantagem do precursor, ou first mover advantage (LIEBERMAN; MONTGOMERY, 1988). 
De acordo com essa linha de pensamento, apenas o precursor em dada indústria - por mais homogênea e de recursos móveis que seja - poderia obter VCS. Barney (1991), entretanto, questiona a efetiva homogeneidade de recursos nessa situação, posto que, caso uma empresa inserida em dada indústria anteveja oportunidades para o desenvolvimento de nova estratégia e obtenha desempenho superior ao da média - o que caracteriza a vantagem do precursor -, essa empresa possui um atributo que não compartilha com as outras: o de antever possibilidades mercadológicas, descaracterizando, assim, a homogeneidade de recursos da indústria, por possuir algo que suas concorrentes não possuem.

Indiscutivelmente não são todos os recursos que podem ser categorizados como recursos estratégicos, como questionam alguns críticos da RBV (SILVERMAN, 2002; WILLIAMSON, 1999), mas sim aqueles que, conforme Barney (1986a, 1986b, 1991), permitem à empresa o desenvolvimento e implementação de estratégias de criação de valor.

Para que tais recursos permitam às empresas o desenvolvimento dessas estratégias, eles devem, segundo Barney (1991), atender a quatro pré-requisitos fundamentais:

[...] deve ser valoroso, no sentido de explorar as oportunidades e/ou neutralizar as ameaças do ambiente no qual a empresa se insere, (b) deve ser raro entre os concorrentes atuais e potenciais de uma firma, (c) deve ser imperfeitamente imitável, e (d) não podem existir substitutos estratégicos equivalentes a esses recursos, substitutos esses que sejam valorosos, mas não sejam raros ou imperfeitamente imitáveis. (Barney, 1991, p. 105-106, tradução nossa).

Os recursos tidos como valorosos devem, segundo Barney (1991), permitir à empresa o aproveitamento das oportunidades e/ou a neutralização das ameaças ambientais, referindo-se ao tradicional modelo SWOT (Strenghts, Weaknesses, Opportunities and Threats) preconizado por Porter $(1980,1985)$, Hofer \& Schendel (1978), Penrose (1959) e Stintchcombe (1965).

A raridade (ou escassez) dos recursos é a segunda condicionante para a compreensão do recurso-fonte de VCS.

Por definição, os recursos valorosos possuídos por um grande número de firmas concorrentes ou potencialmente concorrentes não podem ser fonte de Vantagem Competitiva, sustentável ou não. [...] Se um recurso valoroso em particular é possuído por um grande número de empresas, então cada uma dessas empresas tem a capacidade de explorar tais recursos da mesma forma implementando, portanto, estratégias comuns, que não proveem a nenhuma delas Vantagem Competitiva. (BARNEY, 1991, p. 107, tradução nossa).
Assim, levando-se em consideração a possibilidade de existirem recursos, ou conjunto de recursos, que não se mostram acessíveis a todas as empresas em dada indústria, compreende-se a importância da raridade para a obtenção da VCS. Novamente, o conceito de heterogeneidade, citado por Penrose (1959), pode ser aplicado, sustentando a versão de que nem todos os recursos estão acessíveis a todas as empresas. Diante dessa parcial indisponibilidade, as firmas que detiverem recursos valorosos e raros tendem a obter VCS, desde que tais recursos atendam aos quesitos de imperfeita imitabilidade e substituição.

A posse, por parte de uma firma, de recursos valorosos e raros se mostra condição necessária, mas não suficiente para a obtenção de VCS, pois se tais recursos forem perfeitamente imitáveis, esvai-se o conceito de raridade. Portanto, para que uma empresa possa qualificar dado recurso como fonte de VCS, tal recurso não pode ser imitado por concorrentes atuais ou potenciais. Para isso, é necessária a criação de barreiras à imitação por parte das concorrentes atuais e potenciais mediante combinação de um ou mais de três fenômenos: condição histórica única (path dependency), ambiguidade causal e complexidade social.

O quarto quesito a ser preenchido por recursos tipificados como fonte de VCS é a impossibilidade de substituição. Segundo Barney (1991), não devem existir substitutos estratégicos equivalentes ao recurso para que ele possa gerar VCS. O autor considera que dois grupos de recursos são estrategicamente equivalentes quando cada um deles pode ser explorado separadamente para a implementação de uma mesma estratégia.

\subsection{Conhecimento}

A definição do que seja conhecimento passa, obrigatoriamente, pela epistemologia tradicional que $\mathrm{O}$ define como crença verdadeira e justificada. A despeito de todas as discussões filosóficas que permeiam o tema, Dutra (2001) apresenta três requisitos que devem ser preenchidos quando levado em consideração o conhecimento: i) a crença é verdadeira; ii) certo indivíduo possui tal crença; e iii) ele está justificado em possuir tal crença. Esse autor pondera que, mesmo baseando-se nesses três quesitos existe a possibilidade de não se encontrar o conhecimento e adiciona um quarto elemento: iv) a crença é gerada por um mecanismo confiável de produção de crenças.

Vieira Pinto (1974) compreende o conhecimento como a capacidade do homem de dominar a natureza, transformá-la e adaptá-la às suas necessidades, representando a síntese do todo existente até dada época, contextualizado, historiado e catalogado. Bombassaro (1982) aborda o conhecimento, definindo-o por meio do processo pelo qual o homem compreende o mundo, sendo formado por conjuntos 
de enunciados formais ou não, produzidos pelo homem, dos quais prescinde não apenas para sua sobrevivência, mas também para sua comunicação, interação e vínculo com o coletivo.

Para Davenport e Prusak (1998),

Conhecimento é uma mistura fluida de experiência condensada, valores, informação contextual e insight experimentado, a qual proporciona uma estrutura para a avaliação e incorporação de novas experiências e informações. Ele tem origem e é aplicado na mente dos conhecedores. Nas organizações, ele costuma estar embutido não só em documentos ou repositórios, mas também em rotinas, processos práticas e normas organizacionais (DAVENPORT; PRUSAK, 1998, p. 6).

Partindo-se da conceituação acima, nota-se que a origem do conhecimento organizacional reporta-se à visão de Penrose (1959), que entende a firma como repositório de recursos tanto físicos quanto intangíveis, designado como coleção de recursos produtivos que abarca tanto elementos tangíveis, como unidades fabris, equipamentos, terra e recursos naturais, matérias-primas, produtos semiacabados e recursos humanos disponíveis numa firma, tais quais a mão de obra não qualificada e a qualificada (WEISSENBERGER-EIBL; SCHWENK, 2009).

Adicionalmente, essa visão de Davenport e Prusak (1998) baseia-se nas rotinas inerentes a cada firma, referindo-se a Nelson e Winter (1982) na medida em que compreendem a firma como origem e destino de conhecimentos e como Winter (1998) pondera:

Uma empresa específica em um determinado momento é um repositório de uma faixa de conhecimento produtivo bastante específica, faixa essa que muitas vezes envolve idiossincrasias que distinguem até empresas semelhantes que atuam na(s) mesma(s) linhas(s) de negócios. (WINTER, 1998, p. 175).

Levando-se em consideração a importância estratégica do conhecimento e de seus componentes, Choo (2003) considera a informação como um componente intrínseco de quase tudo que uma organização faz e presente em três esferas nas quais a criação e o uso da informação se mostram fundamentais para o crescimento e a adaptação das empresas: i) dar sentido (criar significado) às mudanças que ocorrem no ambiente externo à organização; ii) criar, organizar e processar as informações com o objetivo de gerar novos conhecimentos; iii) auxiliar na tomada de decisão. Acrescenta ainda que a organização do conhecimento possui informações e conhecimentos que lhe conferem uma especial vantagem, permitindo-lhe agir com inteligência, criatividade e, ocasionalmente, esperteza.
Weick (2002) menciona que a criação do significado é importante ferramenta para que a corporação possa compreender o que ocorre no ambiente no qual está inserida. Nesse caso, a informação tem como principal função a de reduzir a ambiguidade que advém do ambiente externo à corporação, de forma a torná-lo estável e previsível (CHEN, 2007; TOLSTOY, 2009).

Segundo Choo (2003), a criação de significado dentro da firma segue o modelo proposto por Weick (1979). Por meio da criação de significado, os membros de uma corporação analisam o que acontece à sua volta buscando a compreensão dos fatores que motivam as alterações ambientais. Tomam-se por base os fatos identificados e a experiência, objetivando-se a solução das ambiguidades das informações ambientais. Busca-se, por meio da criação dos significados, a compreensão do que ocorre fora das fronteiras da firma, os motivos dessas ocorrências, o seu significado e impactos para a firma. A criação do significado surge no momento em que alguma alteração ambiental (ou ecológica) ocorre e traz impactos ao ambiente da organização, afetando rotinas e fluxos de experiência (WEST, 2008; THERIOU; AGGELIDIS; THERIOU, 2009).

Choo (2003) apresenta a segunda etapa em direção à tomada de decisões com base na explanação de Nonaka e Takeuchi (2004), a criação do conhecimento. Segundo esses dois autores, a criação do conhecimento acorre pela interação entre o conhecimento tácito e explícito, gerando um ciclo criativo, composto por quatro formas de conversão: a socialização, a externalização, a combinação e a internalização, conhecidas pelo acrônimo SECI (VORAKULPIPAT; REZGUI, 2008; HEINRICHS; LIM, 2005; NIELSEN, 2006).

A socialização - conversão do conhecimento tácito para o conhecimento tácito - contempla a aquisição de conhecimento por meio das experiências, modelos mentais e técnicas compartilhadas, com ou sem a expressão pela linguagem. $\mathrm{O}$ treinamento do dia a dia se baseia nessa forma de conversão do conhecimento, cuja chave é a experiência compartilhada. Consequentemente, a transferência de informações deve estar relacionada a emoções e contextos específicos de que as experiências compartilhadas são embutidas. Num contexto organizacional, a própria difusão ou divulgação de determinada habilidade técnica reforça o aspecto de socialização de uma forma de conhecimento, assim como interações com clientes e fornecedores podem vir a ser consideradas parte de um processo infinito de compartilhamento de conhecimento e criação de ideias (NONAKA; TAKEUCHI, 2004).

A externalização - articulação do conhecimento tácito em conceitos explícitos - está fortemente baseada no uso de metáforas e analogias, conceitos e hipóteses. As contradições inerentes às metáforas 
são harmonizadas pela analogia, algo que reduz o desconhecido, destacando o caráter comum entre dois conceitos diferentes. A metáfora é motivada pela intuição e por imagens holísticas e não tem como objetivo encontrar diferenças entre elas. A analogia é realizada pelo pensamento racional e concentra-se nas semelhanças estruturais e funcionais entre dois objetos. A forma de externalização da conversão do conhecimento, de uma forma geral, é vista no processo de criação do conceito. Depois de criados, os conceitos explícitos podem então ser modelados. Em um modelo lógico, não deve haver contradições e todos os conceitos e proposições devem ser expressos em linguagem sistemática, lógica e coerente (NONAKA; TAKEUCHI, 2004).

A combinação - conversão do conhecimento explícito para o conhecimento explícito - consiste da sistematização de conceitos em um sistema conhecido. Envolve a combinação de conjuntos diferentes de conhecimentos explícitos. Numa abordagem organizacional, a gerência de nível médio possui papel decisivo na criação de novos conceitos por meio da rede de informações e conhecimentos codificados. Já, no que diz respeito à alta gerência, o modo de combinação é realizado quando conceitos intermediários são combinados e integrados a conceitos principais. Os indivíduos trocam e combinam conhecimentos por meio de documentos, reuniões, conversas ao telefone ou redes de comunicação computadorizada. A reconfiguração das informações existentes por classificação, acréscimo, combinação e categorização do conhecimento explícito pode levar a novos conhecimentos. A criação do conhecimento realizada pela educação e pelo treinamento formal nas escolas normalmente segue esse padrão (NONAKA; TAKEUCHI, 2004).

A internalização - conversão do conhecimento explícito para o conhecimento tácito - está relacionada ao aprender fazendo e pode ocorrer sem que se tenha de reexperimentar as experiências prévias de outras pessoas. Quando internalizadas nas bases do conhecimento tácito dos indivíduos, sob a forma de modelos mentais ou know-how técnico compartilhado, as experiências tornam-se ativos valiosos. A expansão do escopo da experiência prática é fundamental para o processo de internalização. Para viabilizar o conhecimento organizacional, o conhecimento tácito acumulado precisa ser socializado com os outros membros da organização, iniciando-se, assim, novo ciclo de geração de conhecimento. As formas mais comuns de conversão do conhecimento explícito para o tácito são a verbalização e a diagramação do conhecimento sob a forma de documentos, manuais ou histórias orais (NONAKA; TAKEUCHI, 2004).

\section{Problema de pesquisa}

O problema de pesquisa deste estudo está baseado no entendimento de que o modelo SECI de conversão do conhecimento, proposto por Nonaka e Takeuchi (2004), pode prover à empresa conhecimento necessário para a tomada de decisões em todas as esferas corporativas. Mais, tal processo de conversão caracteriza-se como valoroso, raro, imperfeitamente imitável e imperfeitamente substituível, preenchendo os requisitos básicos da perspectiva da RBV, fundamentada nesse estudo em seus autores seminais (WERNERFELT, 1984; BARNEY 1986b, 1991; BARNEY; ARIKAN 2001).

Assim, a pergunta problema que norteia o estudo é: Na visão do gestor, o processo de criação do conhecimento - SECI - é avaliado como fonte de Vantagem Competitiva Sustentável? Isto é, o Modelo SECI é considerado pelos gestores como sendo, simultaneamente, valoroso, raro, imperfeitamente imitável e imperfeitamente substituível? Em outras palavras, existe convergência entre a prática empresarial e os pressupostos teóricos que caracterizam o SECI como recurso-fonte de Vantagem Competitiva Sustentável?

\section{Procedimentos metodológicos}

\subsection{Amostra}

Este estudo é de natureza descritiva e visou identificar associações entre os dois construtos pesquisados - o modelo SECI e VCS, mediante análise descritiva. A amostra foi por conveniência (SEKARAN, 1992). Embora o planejamento amostral tenha envolvido um cadastro de cerca de 1.900 profissionais que trabalhavam em empresas da indústria, do comércio e de serviços localizados no Estado de São Paulo, a amostra utilizada para a análise dos resultados ficou composta por 200 elementos. O elemento amostral considerado para o estudo foi o administrador, gestor ou funcionário, independente do cargo que ocupava na organização em que atuava. As bases de informantes foram obtidas junto ao CRA - Conselho Regional de Administração em São Paulo e alunos de programas de pós-graduação em programas de administração de empresas.

\subsection{Instrumento de coleta de dados}

Para a coleta dos dados foi desenvolvido questionário estruturado, dividido em três partes. Na primeira foram coletadas informações do perfil da empresa: segmento de atuação, origem, número de filiais, número de funcionários e caracterização do mercado em que a empresa atuava. A segunda parte relacionava o conjunto de atributos associados com o modelo SECI, baseado no questionário 
desenvolvido por Huang e Wang (2002), com as devidas modificações necessárias ao objetivo deste estudo. Para cada um dos 22 atributos (assertivas) considerados nesta pesquisa, o respondente atribuiu nota de zero a dez (LOKEN et al., 1987) para cada um dos quatro vetores conceituais preconizados pela RBV para a obtenção de VCS (valor, raridade, imperfeita imitação e imperfeita substituição), conhecidos pelo acrônimo VRIS. Destaca-se que o fato de analisar as assertivas não significou que a empresa tivesse, formalmente, o modelo SECI incorporado em sua estrutura. Mesmo porque, na prática, a geração de conhecimento organizacional não é tão estruturada como costuma se apresentar em textos acadêmicos que discutem essa questão. Contudo, pode-se supor que as atividades inerentes às assertivas de pesquisa estejam presentes em qualquer organização em maior ou menor grau e, por essa razão, permitiu a aplicação conforme proposto neste estudo. A terceira parte caracterizou o perfil do respondente. Os dados foram analisados utilizando-se o software estatístico SPSS, versão 11.0.

A formulação da assertiva visando à obtenção da avaliação numérica pelo respondente é exemplificada conforme se apresenta no Quadro 1.

O pressuposto na formulação dessa forma era que avaliações mais altas para Valor e mais baixas para Raridade, Imitação e Substituição, simultaneamente revelariam uma orientação mais forte para VRIS, no atributo, conforme previsto no modelo proposto por Barney (1991).

\section{Resultados}

\subsection{Descrição da amostra}

A maioria dos respondentes trabalhava em empresas do ramo de serviços e, em sua maior parte, com até 500 funcionários. A origem dessas empresas era predominantemente nacional e tendiam a possuir menos de dez filiais, conforme pode se observar na Tabela 1, que também inclui o perfil dos respondentes.

No que tange à qualificação dos respondentes, nota-se que a maioria dos respondentes era do gênero masculino, até 30 anos de idade. Contudo, identificou que, para um terço da amostra, a idade dos informantes superava 40 anos de idade. Metade da amostra consistiu de profissionais com cargos de direção, gerência ou supervisão. Embora não presente na Tabela 1, pôde-se identificar que $44 \%$ dos informantes possuíam mais de 5 anos de educação após a conclusão do ensino médio.

Nota-se, pela análise da Tabela 2, que mais de $50 \%$ dos respondentes afirmaram que suas empresas estão inseridas em mercados com muitas empresas e forte concorrência, ao passo que apenas $2 \%$ dos respondentes afirmaram que sua empresa é a única do mercado em que atua.

\subsection{Mensuração de Vantagem Competitiva Sustentável (VRIS) do modelo SECI}

\subsubsection{Avaliação individual dos atributos}

A Tabela 3 foi elaborada por meio da análise de cada uma das respostas assinaladas pelos 200 respondentes, levando-se em consideração as notas atribuídas para os quatro quesitos VRIS para cada uma das assertivas (atributos) das quatro dimensões SECI. Para a sua elaboração foi adotado o seguinte procedimento estatístico. Para cada um dos 22 atributos (assertivas) avaliados, foi feita uma análise de cluster, visando a segmentação em dois grupos de respondentes. Quatro variáveis foram utilizadas para a aplicação dessa técnica: valor, raridade, imitação e substituição. Portanto, cada atributo tinha 200 notas em cada um desses quatro quesitos. Um dos grupos formados consistiu em informantes que atribuíram, simultaneamente, notas elevadas para os quatro quesitos. Portanto, imputaram valores elevados ao atributo associado com valor e consideraram que era fácil encontrá-lo entre os concorrentes (menos raro), era fácil para ser imitado e era fácil para ser substituído. Dessa maneira, se constituiu num grupo que avaliou o atributo como não trazendo Vantagem Competitiva. Já o outro grupo avaliou que o valor do atributo era alto, difícil de ser encontrado nos concorrentes, difícil de ser imitável e difícil de ser substituído. Essa avaliação implicava que o atributo era considerado, simultaneamente, VRIS e, portanto,

Quadro 1. Exemplo de formulação das assertivas de pesquisa.

\begin{tabular}{|c|c|c|c|c|}
\hline Quesito VRIS & Valor & Raridade & Imitação & Substituição \\
\hline $\begin{array}{l}\text { A forma } \\
\text { como nos } \\
\text { comunicamos }\end{array}$ & $\begin{array}{l}\text { Agrega Valor às } \\
\text { nossas atividades }\end{array}$ & $\begin{array}{c}\text { É facilmente } \\
\text { Encontrada entre } \\
\text { nossos concorrentes }\end{array}$ & $\begin{array}{c}\text { Pode ser Copiada } \\
\text { por nossos } \\
\text { concorrentes }\end{array}$ & $\begin{array}{l}\text { Pode ser Substituída por } \\
\text { formas equivalentes por } \\
\text { nossos concorrentes }\end{array}$ \\
\hline & Nota de 0 a 10 & Nota de 0 a 10 & Nota de 0 a 10 & Nota de 0 a 10 \\
\hline É VRIS & Nota alta & \multicolumn{3}{|c|}{ Todas as notas devem ser baixas, simultaneamente. } \\
\hline Não é VRIS & Nota alta & \multicolumn{3}{|c|}{ Pelo menos uma das notas não é baixa. } \\
\hline
\end{tabular}


Tabela 1. Descrição da amostra.

\begin{tabular}{|c|c|c|c|c|c|}
\hline Ramo & Absoluto & $\%$ & Origem & Absoluto & $\%$ \\
\hline Comércio & 35 & 17,5 & Nacional & 147 & 73,5 \\
\hline Serviços & 123 & 61,5 & Estrangeira & 41 & 20,5 \\
\hline Indústria & 42 & 21,0 & Não Informado & 12 & 6,0 \\
\hline \multicolumn{3}{|c|}{ Funcionários } & \multicolumn{3}{|c|}{$\mathrm{N}^{o}$ de filiais } \\
\hline Até 100 & 76 & 38,0 & Nenhuma & 100 & 50,0 \\
\hline De 101 a 500 & 43 & 21,5 & De 1 a 10 & 65 & 32,5 \\
\hline De 501 a 1.000 & 10 & 5,0 & De 11 a 50 & 20 & 10,0 \\
\hline Mais de 1.000 & 56 & 28,0 & Mais de 50 & 13 & 6,5 \\
\hline Não Informado & 15 & 7,5 & Não informado & 2 & 1,0 \\
\hline \multicolumn{3}{|c|}{ Idade do informante } & \multicolumn{3}{|c|}{ Cargo ocupado } \\
\hline Até 30 anos & 95 & 47,5 & & & \\
\hline 31 a 40 anos & 39 & 19,5 & Presidente/diretor & 34 & 17,0 \\
\hline Mais de 40 anos & 66 & 33,0 & Gerente & 32 & 16,0 \\
\hline Gênero & & & Supervisor & 34 & 17,0 \\
\hline Masculino & 125 & 62,5 & Analista & 49 & 24,5 \\
\hline Feminino & 75 & 37,5 & Outros & 51 & 25,5 \\
\hline Total & 200 & 100,0 & Total & 200 & 100,0 \\
\hline
\end{tabular}

Tabela 2. Caracterização do mercado no qual a empresa atua.

\begin{tabular}{lrr}
\hline \multicolumn{1}{c}{ Caracterização do mercado no qual a empresa atua } & Frequência & \% \\
\hline Muitas empresas, forte concorrência & 102 & 51,0 \\
Muitas empresas, fraca concorrência & 7 & 3,5 \\
Poucas empresas, forte concorrência & 40 & 20,0 \\
Poucas empresas, fraca concorrência & 14 & 7,0 \\
Poucas empresas muito grandes, muitas pequenas (pequena) & 13 & 10,0 \\
Poucas empresas muito grandes, muitas pequenas (é grande) & 4 & 6,5 \\
Monopólio & 200 & 2,0 \\
Total & 400,0 \\
\hline
\end{tabular}

poderia trazer Vantagem Competitiva Sustentável. A Tabela apresenta a quantidade de informantes para cada atributo, segundo os dois grupos identificados na análise bem como as respectivas médias das notas.

Para ilustrar a leitura dessa tabela, são comentados os números relativos ao primeiro atributo dela: 'compartilhamento de informações'. Assim, pela análise de cluster, foi identificado que 76 (38\%) dos informantes atribuíram altas notas para valor $(6,78)$ e baixas notas para raridade $(4,43)$, imitação $(4,08)$ e substituição $(4,24)$. Portanto, consiste num grupo que avaliou o atributo como sendo um fator de Vantagem Competitiva Sustentável, segundo o modelo proposto por Barney (1991). Por outro lado, os demais 124 (62,0\%) informantes atribuíram uma alta média para valor $(8,40)$ e altas médias para raridade $(7,47)$, imitação $(7,70)$ e substituição $(6,90)$. Nesse caso, esse grupo não avaliou que o atributo pudesse ser considerado uma Vantagem Competitiva Sustentável, pois entenderam que era fácil de encontrar na concorrência, fácil de ser imitado e fácil de ser substituído. Para os demais atributos, a leitura é similar, podendo-se notar, em todos os 22 atributos, que a proporção de informantes situados no primeiro grupo ficou ao redor de $40,0 \%$.

\subsubsection{Avaliação na dimensão SECI}

Ainda que pela Tabela 3 tenha sido possível caracterizar os dois tipos de grupos, dentro do atributo, isso por si só não revela que o modelo SECI seja uma Vantagem Competitiva Sustentável. Para isso, é necessário que, simultaneamente, os 22 atributos sejam avaliados como VRIS. Para identificar se isso ocorria, adotou-se um segundo critério de análise. Dentro da cada dimensão SECI, foi avaliado se os atributos contidos nela foram simultaneamente caracterizados como VRIS. Assim, ao primeiro grupo (VRIS) pela análise de cluster feita anteriormente foi atribuído o valor 1. Logo, cada um dos 200 informantes ficou associado a um valor 1 ou valor 2 no atributo, relativo à sua particular avaliação. 
Tabela 3. Mensuração VRIS segundo atributos do SECI.

\begin{tabular}{|c|c|c|c|c|c|c|c|}
\hline \multirow{3}{*}{$\begin{array}{l}\text { Atributos relativos à: } \\
\text { Socialização }\end{array}$} & \multirow{2}{*}{\multicolumn{3}{|c|}{$\begin{array}{l}\text { Classificado como } \\
\text { VRIS }\end{array}$}} & \multirow{3}{*}{$\begin{array}{l}\text { Agrega } \\
\text { Valor }^{(1)}\end{array}$} & \multicolumn{3}{|c|}{ É fácil(2) } \\
\hline & & & & & \multirow{2}{*}{$\begin{array}{c}\text { Encontrar } \\
\text { Média }\end{array}$} & \multirow{2}{*}{$\begin{array}{l}\text { Imitar } \\
\text { Média }\end{array}$} & \multirow{2}{*}{$\frac{\text { Substituir }}{\text { Média }}$} \\
\hline & $\mathbf{S} / \mathbf{N}$ & $\mathbf{N}$ & $\%$ & & & & \\
\hline \multirow[t]{2}{*}{ Compartilhamento das informações } & Sim & 76 & 38,0 & 6,78 & 4,43 & 4,08 & 4,24 \\
\hline & Não & 124 & 62,0 & 8,40 & 7,47 & 7,70 & 6,90 \\
\hline \multirow{2}{*}{$\begin{array}{l}\text { Compreensão de pensamentos e opiniões de } \\
\text { nossos colegas }\end{array}$} & Sim & 90 & 45,0 & 7,27 & 4,83 & 3,97 & 3,96 \\
\hline & Não & 110 & 55,0 & 7,79 & 7,30 & 7,43 & 7,49 \\
\hline \multirow{2}{*}{$\begin{array}{l}\text { Contribuição para o enriquecimento das } \\
\text { discussões }\end{array}$} & Sim & 98 & 49,0 & 7,06 & 4,65 & 4,52 & 4,34 \\
\hline & Não & 102 & 51,0 & 8,32 & 7,23 & 7,70 & 7,31 \\
\hline \multirow{2}{*}{$\begin{array}{l}\text { Encorajamento aos colegas para que exprimam } \\
\text { suas ideias }\end{array}$} & $\operatorname{Sim}$ & 103 & 51,5 & 6,64 & 4,55 & 4,26 & 4,17 \\
\hline & Não & 97 & 48,5 & 8,12 & 7,48 & 7,76 & 7,57 \\
\hline \multirow[t]{2}{*}{ Coleta de informações antes de reuniões } & Sim & 78 & 39,0 & 6,99 & 4,31 & 4,01 & 4,15 \\
\hline & Não & 122 & 61,0 & 8,00 & 7,48 & 7,60 & 7,34 \\
\hline \multirow{2}{*}{$\begin{array}{l}\text { Observação e cópia do comportamento dos } \\
\text { colegas de empresa }\end{array}$} & Sim & 82 & 41,0 & 6,77 & 4,48 & 4,09 & 3,85 \\
\hline & Não & 118 & 59,0 & 8,15 & 7,70 & 7,75 & 7,35 \\
\hline \multicolumn{8}{|l|}{ Externalização } \\
\hline \multirow[t]{2}{*}{ Criação de modelos para explicar ideias } & Sim & 111 & 55,5 & 7,36 & 4,86 & 4,40 & 4,51 \\
\hline & Não & 89 & 44,5 & 8,24 & 6,01 & 8,11 & 7,67 \\
\hline \multirow{2}{*}{$\begin{array}{l}\text { Transformação de pensamentos complexos em } \\
\text { ideias concretas }\end{array}$} & Sim & 92 & 46,0 & 6,93 & 4,50 & 4,09 & 4,24 \\
\hline & Não & 108 & 54,0 & 7,54 & 6,94 & 7,40 & 7,42 \\
\hline \multirow{2}{*}{$\begin{array}{l}\text { Descrição de termos técnicos em linguagem } \\
\text { coloquial }\end{array}$} & Sim & 70 & 35,0 & 5,49 & 3,79 & 3,50 & 3,33 \\
\hline & Não & 130 & 65,0 & 7,44 & 6,96 & 7,18 & 6,88 \\
\hline \multirow{2}{*}{$\begin{array}{l}\text { Explicação de conceitos abstratos por meio de } \\
\text { exemplos simples }\end{array}$} & Sim & 84 & 42,0 & 7,00 & 4,37 & 3,86 & 3,75 \\
\hline & Não & 116 & 58,0 & 8,13 & 7,29 & 7,34 & 7,50 \\
\hline \multirow{2}{*}{$\begin{array}{l}\text { Utilização de analogias para explicação de } \\
\text { conceitos abstratos }\end{array}$} & $\operatorname{Sim}$ & 87 & 43,5 & 6,66 & 4,41 & 4,17 & 3,92 \\
\hline & Não & 113 & 56,5 & 7,58 & 7,23 & 7,19 & 7,32 \\
\hline \multirow[t]{2}{*}{ Auxílio à expressão dos colegas } & Sim & 87 & 43,5 & 7,03 & 4,56 & 4,28 & 3,59 \\
\hline & Não & 113 & 56,5 & 8,14 & 7,31 & 7,06 & 7,41 \\
\hline Combinação & & & & & & & \\
\hline Organização de ideias em discussão & $\operatorname{Sim}$ & 78 & 39,0 & 7,04 & 4,46 & 3,64 & 3,73 \\
\hline & Não & 122 & 61,0 & 7,76 & 7,07 & 7,64 & 7,53 \\
\hline Utilização de experiências pessoais para busca de & $\operatorname{Sim}$ & 72 & 36,0 & 7,69 & 4,63 & 3,72 & 3,44 \\
\hline soluções & Não & 128 & 64,0 & 8,40 & 7,40 & 7,21 & 7,22 \\
\hline Organização de resumos ao término de reuniões & $\operatorname{Sim}$ & 80 & 40,0 & 6,50 & 4,36 & 3,66 & 3,66 \\
\hline & Não & 120 & 60,0 & 7,43 & 7,54 & 7,08 & 7,51 \\
\hline Organização mental de assuntos discutidos em & Sim & 57 & 28,5 & 6,09 & 3,82 & 3,32 & 3,23 \\
\hline reuniões & Não & 143 & 71,5 & 7,89 & 6,84 & 6,76 & 6,87 \\
\hline Coleta de informações e comparação às & Sim & 78 & 39,0 & 6,86 & 4,77 & 4,00 & 3,90 \\
\hline existentes na busca por novas ideias & Não & 122 & 61,0 & 8,32 & 7,43 & 7,48 & 7,57 \\
\hline Organização e estruturação de conceitos & Sim & 80 & 40,0 & 6,18 & 4,08 & 3,73 & 3,81 \\
\hline ambíguos para facilitar compreensão & Não & 120 & 60,0 & 7,37 & 7,14 & 6,99 & 7,17 \\
\hline Internalização & & & & & & & \\
\hline Comparação de novas ideias às experiências & $\operatorname{Sim}$ & 90 & 45,0 & 7,32 & 4,68 & 4,29 & 3,74 \\
\hline prévias & Não & 110 & 55,0 & 7,87 & 7,32 & 6,92 & 7,47 \\
\hline Busca por confirmação de ideias e conceitos & Sim & 70 & 35,0 & 6,16 & 3,97 & 3,67 & 3,93 \\
\hline expressos por colegas & Não & 130 & 65,0 & 8,12 & 7,25 & 6,94 & 7,04 \\
\hline Certificação de que os colegas de trabalho foram & Sim & 78 & 39,0 & 6,82 & 4,38 & 3,67 & 3,71 \\
\hline compreendidos & Não & 122 & 61,0 & 7,48 & 7,16 & 7,18 & 7,25 \\
\hline Concessão de tempo aos colegas para que & Sim & 91 & 45,5 & 5,66 & 4,42 & 3,64 & 3,96 \\
\hline reflitam a respeito do tema & Não & 109 & 54,5 & 7,60 & 6,95 & 7,34 & 7,30 \\
\hline
\end{tabular}

${ }^{(1)}$ Quanto maior a nota atribuída, maior a orientação para VCS. ${ }^{(2)}$ Quanto menor a nota atribuída maior orientação para Raridade, Não Imitação e Não Substituição. Portanto, maior orientação para VCS. 
Tabela 4. Mensuração de VRIS segundo a dimensão SECI.

\begin{tabular}{|c|c|c|c|c|c|c|c|}
\hline \multirow[t]{2}{*}{ Dimensão do SECI } & \multicolumn{3}{|c|}{ Classificação } & \multirow{2}{*}{$\begin{array}{l}\text { Agrega } \\
\text { valor }\end{array}$} & \multicolumn{3}{|c|}{ É fácil } \\
\hline & & $\mathbf{N}$ & $\%$ & & Encontrar & Imitar & Substituir \\
\hline \multirow[t]{2}{*}{ Socialização } & VRIS & 23 & 11,5 & 6,64 & 4,10 & 3,67 & 3,48 \\
\hline & Não é VRIS & 177 & 88,5 & 7,72 & 6,44 & 6,43 & 6,23 \\
\hline \multirow[t]{2}{*}{ Externalização } & VRIS & 23 & 11,5 & 6,98 & 3,84 & 3,38 & 3,12 \\
\hline & Não é VRIS & 177 & 88,5 & 7,43 & 6,25 & 6,28 & 6,19 \\
\hline \multirow[t]{2}{*}{ Combinação } & VRIS & 17 & 8,5 & 6,79 & 3,76 & 2,75 & 2,88 \\
\hline & Não é VRIS & 183 & 91,5 & 7,51 & 6,39 & 6,18 & 6,23 \\
\hline \multirow[t]{2}{*}{ Internalização } & VRIS & 33 & 16,5 & 6,13 & 3,85 & 3,32 & 3,33 \\
\hline & Não é VRIS & 167 & 83,5 & 7,47 & 6,46 & 6,23 & 6,35 \\
\hline \multirow[t]{2}{*}{ Geral } & VRIS & 7 & 3,5 & 6,42 & 3,03 & 2,37 & 2,67 \\
\hline & Não é VRIS & 193 & 96,5 & 7,45 & 6,20 & 6,05 & 6,00 \\
\hline
\end{tabular}

Se ele tivesse um vetor $[1,1,1,1,1,1$,$] referente aos$ seis atributos da dimensão Socialização, ele seria classificado como sendo VRIS para Socialização, recebendo, agora, um novo código 1. Isto é, teria avaliado que a dimensão Socialização era uma Vantagem Competitiva Sustentável. Por outro lado, caso o vetor contivesse algum valor diferente de 1 , ele não seria considerado VRIS. A Tabela 4 apresenta a resultante dessa nova classificação.

Nota-se, agora, que apenas 23 (11,5\%) dos informantes caracterizaram simultaneamente que os seis atributos de Socialização eram Vantagem Competitiva Sustentável, cujas médias na dimensão foram: valor $(6,64)$, raridade $(4,10)$, imitação $(3,67)$ e substituição $(3,48)$. Para a dimensão Externalização, o percentual foi o mesmo (11,5\%). Já para Combinação, o percentual ficou em 8,5\% e para Internalização ficou em 16,5\%. Ainda assim, esses quatro percentuais não definiam se o modelo SECI poderia ser considerado, na visão dos gestores, como uma Vantagem Competitiva Sustentável, devido à necessidade de simultaneidade nas quatro dimensões. Mais uma vez foi criado um algoritmo para essa identificação. Assim, se cada um dos 200 informantes tinha sido classificado como tendo o vetor $[1,1,1,1]$ relativo à avaliação de Socialização e das outras três dimensões como sendo VRIS, então ele seria classificado com alguém que avaliou o modelo SECI como trazendo uma Vantagem Competitiva Sustentável para a organização. Qualquer valor diferente de 1 no vetor implicaria em não caracterização como VRIS. A Tabela 4, última linha, reflete a resultante dessa análise. Pode ser verificado que apenas $7(3,5 \%)$ dos informantes entendiam dessa forma. Nesse caso, as médias desse grupo foram: valor $(6,42)$, raridade $(3,03)$, imitação $(2,37)$ e substituição $(2,67)$.

A Figura 1 sintetiza os valores médios identificados para ambos os grupos que avaliaram o modelo SECI. Nota-se que o quadrilátero interno representa as médias associadas ao grupo que entendeu que o modelo

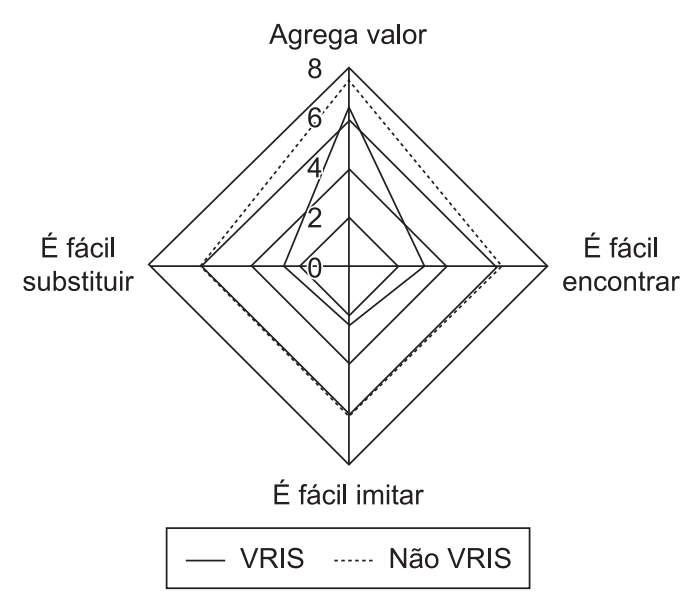

Figura 1. Composição de médias VRIS para SECI.

SECI poderia ser caracterizado como uma Vantagem Competitiva sustentada. Já o quadrilátero externo representa as médias daqueles que caracterizaram o SECI como não sendo, em sua totalidade, uma Vantagem Competitiva Sustentável.

\section{Conclusão}

Conforme apresentado nas Tabelas 3 e 4 deste estudo, nota-se que apenas 3,5\% dos respondentes avaliaram os atributos da dimensão socialização, externalização, combinação e internalização como sendo, simultaneamente valorosos, raros imperfeitamente imitáveis e imperfeitamente substituíveis (VRIS). Embora a teoria afirme que o SECI seja uma Vantagem Competitiva Sustentável, não é o que se entende na prática, tendo em vista que a avaliação dos gestores pesquisados diverge completamente do modelo teórico.

Pelos resultados desta amostra, há evidências em concluir que a criação do conhecimento possa ser um fator que contribua para a obtenção apenas 
de Vantagem Competitiva. De acordo com Barney (1991), a Vantagem Competitiva é aquela que advém da impossibilidade dos concorrentes de uma empresa em adotar estratégias de geração de valor ao mesmo tempo que a empresa. Assim, diante das elevadas médias atribuídas a todos os atributos das quatro dimensões do modelo SECI no que tange ao valor que agregam à oferta da empresa - atributo "valor" preconizado pela RBV - compreende-se que deste pode advir Vantagem Competitiva, desde que pelo menos um dos outros quesitos da VRIS - raridade ou não imitação ou não substituição - estejam presentes, isto é, uma avaliação baixa, pela escala utilizada nesta pesquisa.

Compreende-se que, a despeito dos pressupostos de heterogeneidade e imobilidade de recursos indicarem a pequena possibilidade de empresas numa mesma indústria terem acesso aos mesmos recursos (PENROSE, 1959; BARNEY, 1991), em especial os originados a partir do conhecimento (CHOO, 2003), constata-se que os respondentes não avaliam o conhecimento gerado a partir do modelo SECI como recurso imóvel e heterogêneo, contradizendo claramente o modelo teórico, mesmo que baseado pura e simplesmente no aspecto da intangibilidade, difícil mensuração e compreensão de origens dos recursos advindos do conhecimento (DAVENPORT; PRUSAK, 1998, HITT; IRELAND; HOSKINSSON, 2002; GRANT, 2002).

Ainda que se tenha constatado a rejeição da hipótese em teste neste estudo, bem como se especule a não aderência do modelo teórico à prática empresarial, considera-se que a característica essencial do processo de tomada de decisões reside na criação do significado e na conversão do conhecimento (CHOO, 2003).

Diante do método adotado para a presente pesquisa, importantes limitações se apresentam, especialmente pela incapacidade do pesquisador em prover ao respondente base teórica para que possa analisar o instrumento de pesquisa.

Uma das possíveis limitações deste estudo está condicionada ao pouco, ou nenhum, conhecimento do respondente acerca da teoria que permeia o estudo, o que pode ter conduzido o resultado da pesquisa à rejeição da hipótese formulada (SECI não é VRIS).

Outros aspectos limitantes podem ser caracterizados pela composição não probabilística da amostra. Leve-se em consideração também a possibilidade de falha na composição do instrumento de pesquisa que, muito embora baseado em pesquisas já realizadas por outros autores (HUANG; WANG, 2002), talvez possa ter se mostrado longo e complexo demais para os respondentes.

Do ponto de vista acadêmico, a contribuição do estudo situa-se no desenvolvimento e aplicação de um modelo que procura operacionalizar os dois conceitos estudados, objetivando a sua mensuração, permitindo uma aproximação do contexto teórico para o prático. Do ponto de vista aplicado entende-se que o estudo traz como contribuição a possibilidade de uso do instrumento de coleta desenvolvido que poderá auxiliar na identificação de pontos de atenção organizacional, associados com os atributos relativos ao SECI. Dessa forma, a sua aplicação trará indicadores métricos que, analisados sob a ótica gerencial, podem suscitar ações corretivas quanto à criação de conhecimento organizacional. Isso porque, cada atributo, em si, embute uma ação relativa à criação de conhecimento organizacional. Uma aplicação deste instrumento a todos os empregados de uma organização permite a ela identificar onde estão pontos críticos que deverão ser aprimorados, visando uma utilização mais eficaz do conhecimento organizacional.

Como continuidade do estudo seria interessante que, além de uma pesquisa quantitativa, também fosse conduzida uma pesquisa qualitativa. Como ela seria possível averiguar com mais precisão as razões da rejeição da hipótese embutida neste trabalho. Aparentemente os assuntos abordados se mostram complexos demais para o respondente. Avalia-se que, por meio de questionários semiestruturados, aplicados a uma amostra menor de respondentes, possa se obter respostas mais específicas que permitam identificar as causas que possam explicar a divergência encontrada entre o que preconiza a teoria e o que efetivamente acontece na prática.

\section{Agradecimentos}

Ao Mackpesquisa - Fundo de Apoio à Pesquisa da Universidade Presbiteriana Mackenzie - pelo apoio financeiro para a realização da coleta dos dados e editoração do texto do projeto que permitiu a elaboração do presente artigo.

\section{Referências}

BAIN, J. S. Barriers to new competition. Cambridge, MA: Harvard University Press, 1956.

BARNEY, J. B. Strategic factor markets: expectations, luck and business strategy. Management Science, p. 1231-1241, 1986(a).

BARNEY, J. B. Organizational culture: can it be a source of sustainable competitive advantage? The Academy of Management Review, v. 11, n. 3, p. 656-665, 1986(b).

BARNEY, J. B. Firm resources and sustainable competitive advantage. Journal of Management, v. 17, p. 99-120, 1991.

BARNEY, J. B.; ARIKAN, A. M. The resource-based view: origins and implications. In HITT, M. A.; FREEMAN, R. E.; HARRISON, J. S. (Ed.). Handbook of strategic management. Oxford: Blackwell, 2001.

BOMBASSARO, L. C. As fronteiras da epistemologia: como se produz o conhecimento. Petrópolis, RJ: Vozes, 1982. 
CHEN, C.-N. Analysis of the knowledge creation process: na organizational change perspective. International Journal of Organization Theory and Behavior, v. 10, n. 3, p. 287-313, 2007.

CHOO, C. W. A organização do conhecimento: como as organizações usam a informação para criar significado, construir conhecimento e tomar decisões. São Paulo: Senac, 2003.

COLLINS, D. J. How valuable are organizational capabilities? Strategic Management Journal, v. 15, p. 143-152, 1994.

DAVENPORT, T. H.; PRUSAK, L. Conhecimento empresarial: como as organizações gerenciam o seu capital intelectual. Rio de Janeiro: Campus, 1998.

DAWES, J. Five point vs. eleven point scales: does it make a difference to data characteristics? Australasian Journal of Market Research, v. 10, n. 1, 2002.

DUTRA, L. H. A. Verdade e investigação: o problema da verdade na teoria do conhecimento. São Paulo: EPU, 2001.

ELG, M. The process of constructing performance measurement. The TQM Magazine, v. 19, n. 3, p. 217-228, 2007.

GRANT, R. M. Direccion estratégica, conceptos, técnicas y aplicaciones. Madrid: Graficas Rogar, 2002.

HEINRICHS, J. H.; LIM, J.-S. Model for organizational knowledge creation and strategic use of information. Journal of the American Society for Information Science and Technology, v. 56, n. 6, p. 620-629, 2005.

HITT, M. A.; IRELAND, R. D.; HOSKINSSON, R. E. Administração estratégica. São Paulo: PioneiraThompson, 2002.

HO, C.-T. The relationship between knowledge management enablers and performance. Industrial Management \& Data Systems, v. 109, n. 1, p. 98-117, 2009.

HOFER, W. C.; SCHENDEL, D. Strategy formulation: analytical concepts. St. Paul, MN: West, 1978.

HUANG, J.; WANG, S. Knowledge conversion abilities and knowledge creation and innovation: a new perspective on team composition. In: European Conference on Organizational Knowledge, Learning and Capabilities, 3., 2002.

LIEBERMAN, M. B.; MONTGOMERY, D. B. First mover advantages. Strategic Management Journal, v. 9, p. 41-58, 1988.

LOKEN, B. et al. The use of 0-10 Scales in Telephone Surveys. Journal of the Market Research Society, v. 29, n. 3, 1987.

NELSON, R. R.; WINTER, S. G. An evolutionary theory of economic change. Cambridge, MA: Harvard University Press, 1982.

NIELSEN, A. P. Understanding dynamic capabilities through knowledge management. Journal of Knowledge Management, v. 10, n. 4, p. 59-71, 2006.

NONAKA, I.; TAKEUCHI, H. Criação do conhecimento na empresa: como as empresas japonesas geram a dinâmica da inovação. Rio de Janeiro: Elsevier, 2004.
PENROSE, E. T. The theory of the growth of the firm. New York: Willey, 1959.

PORTER, M. E. Competitive strategy. New York: Free Press, 1980.

PORTER, M. E. Competitive advantage. New York: Free Press, 1985.

RUMELT, R. Toward a strategic theory of the firm. In: LAMB, R. (Ed.). Competitive strategic management. Englewood Cliffs, NJ: Prentice-Hall, 1984.

SEKARAN, U. Research methods for business: a skillbuilding approach. 2. ed. New York: John Wiley \& Sons, 1992.

SILVERMAN, B. 2002. Organizational economics. In: BAUM, J. A. C. (Ed.). Companion to organizations. Oxford: Blackwell Publishing, 2002. p. 233-256.

STINTCHCOMBE, A. L. Social structure and organizations. In: MARCH, J. G. (Ed.). Handbook of organizations. Chicago: Rand-McNally, 1965. p. 142-193.

THERIOU, N. G.; AGGELIDIS, V.; THERIOU, G. N. A theoretical framework contrasting the resource-based perspective and the knowledge-based view. European Research Studies, v. 12, n. 3, 2009.

TOLSTOY, D. Knowledge combination and knowledge creation in a foreign-market network. Journal of Small Business Management, v. 47, n. 2, p. 202-220, 2009.

VIEIRA PINTO, A. Ciência existência: problemas filosóficos da pesquisa científica. Rio de Janeiro: Paz e Terra, 1974.

VORAKULPIPAT, C.; REZGUI, Y. An evolutionary and interpretative perspective to knowledge management. Journal of Knowledge Management, v. 12, n. 3, p. 17-34, 2008.

WEICK, K. E. The social psycology of organizing. 2. ed. New York: Random House, 1979.

WEICK, K. E. Making sense of the organization. Oxford, UK; Malden, MA: Blackwell, 2002.

WEISSENBERGER-EIBL, M.; SCHWENK, J. "Lifeblood knowledge": dynamic relational capabilities (DRC) and knowledge for firm innovativeness and competitive advantage. Measuring Business Excellence, v. 13, n. 2, p. 7-16, 2009.

WERNERFELT, B. A resource-based view of the firm. Strategic Management Journal, v. 5, p. 171-180, 1984.

WERNERFELT, B. Resource-based strategy in a stochastic model. In: MONTGOMERY, C. Resource-based and evolutionary theories of the firm - towards a synthesis. Massachusetts: Kluwer Academic Publishers, 1995.

WEST, C. J. A methodological framework for improving knowledge creation teams. Engineering Management Journal, v. 20, n. 2, p. 3-13, 2008.

WILLIAMSON, O. E. Strategy research: governance and competence perspectives. Strategic Management Journal, v. 20, n. 12, 1087-1108, 1999.

WINTER, S. G. On case, competence and the corporation. Journal of Law, Economics and Organization, v. 4, n. 1, p. 163-180, 1998. 